\title{
On the Electrocardiographic Findings in the Gastrointestinal Diseases, Especially on the Changes in the RS-T Segment and $T$ Wave
}

\author{
Kiyoto SATAKE, M. D.* and Eiichi KIMURA, M. D.**
}

The changes in the RS-T segment and $\mathrm{T}$ wave are not infrequently observed in electrocardiograms of various gastrointestinal diseases. The nature and the clinical significance of these findings were discussed in this report.

The RS-T and T changes observed in gastrointestinal cancer, liver cirrhosis and hepatitis are considered to be ascribed to the hypalbuminemia and/or the hypopotassemia.

In the biliary tract diseases, the RS-T and $T$ changes can be attributed to the coronary disorders, which may be functional, organic or both.

The changes observed in peptic ulcer and gastroptosis may be interpreted to be due to the autonomic nervous dysregulation or circulatory dysfunction.

$\mathrm{V}$ ARIOUS gastrointestinal diseases often show the electrocardiographic changes, although the cardiovascular symptoms are not always significant. The changes in the RS-T segment and $T$ wave, the abnormal stimulus formation such as extrasystoles, the abnormal conduction, the changes in the QT interval, etc., have been reported to be observed in these diseases. ${ }^{1)}$ The purpose of this report is to study the nature and the clinical significance of these findings, especially, of the depression of the RS-T segment and lowering of the $T$ wave.

\section{Materials and Methods}

\section{Clinical Meterials-}

A total number of 331 cases of gastrointestinal disease were studied. The cases consist of 57 with gastrointestinal cancer, 19 with liver cirrhosis, 26 with

From the Department of Internal Medicine, Nippon Medical School, Tokyo.

Read before the 47th Annual Meeting of the Japanese Gastrointestinal Society held in Tokyo on March 31, 1961, as Appointed Lecture.

* Associate Professor of Internal Medicine.

** Professor of Internal Medicine. 
hepatitis, 82 with biliary tract diseases including cholelithiasis and cholecystitis, 93 with gastric and/or duodenal ulcer and 54 with gastroptosis. The examinations of the blood, especially of serum protein and potassium, were carried out at the time of electrocardiographic examination, presuming that the level of these substances may contribute to the electrocardiographic findings in these diseases. The concentration of the total serum protein was determined refractometrically, the serum protein fractions were analysed by paper electrophoresis and the serum potassium level was measured by flamephotometry.

In 23 cases with biliary tract diseases the electrocardiogram was obtained during an acute colic attack. In 7 of these cases, double two-step exercise test or anoxia test using a mixture of $10 \%$ oxygen and $90 \%$ nitrogen was performed.

In cases with peptic ulcer or gastroptosis, electrocardiograms were taken in the upright position and the incidence of lowering of the $T$ wave in this posture was examined. The method and diagnostic criteria for standing test are to be reported elsewhere. ${ }^{2)}$

\section{Autopsied Materials-}

A total number of 1,447 autopsy records in the Pathological Department of the Tohoku University Medical School in Sendai from 1950 to 1959 were investigated concerning the association of the coronary sclerosis with the gallbladder diseases.

\section{RESULTS}

1. Gastrointestinal cancer, liver cirrhosis and hepatitis

In our series, the changes in the RS-T segment and/or $T$ wave were

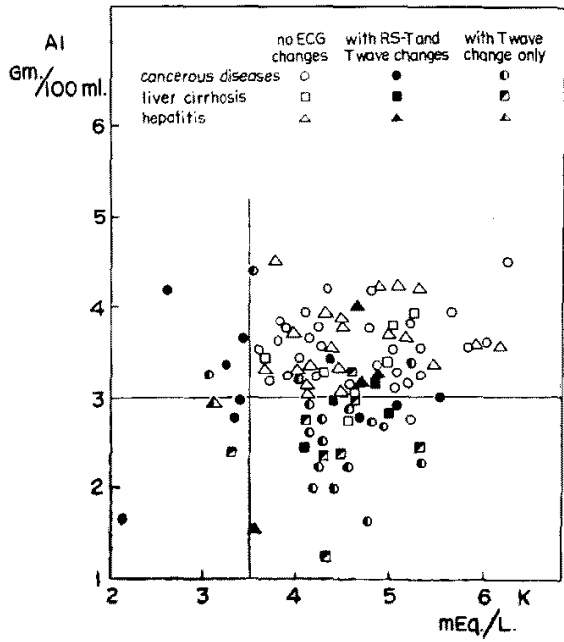

Fig. 1. Relationship of RS-T and T changes to serum albumin and serum potassium in gastrointesinal cancer, liver cirrhosis and hepatitis.

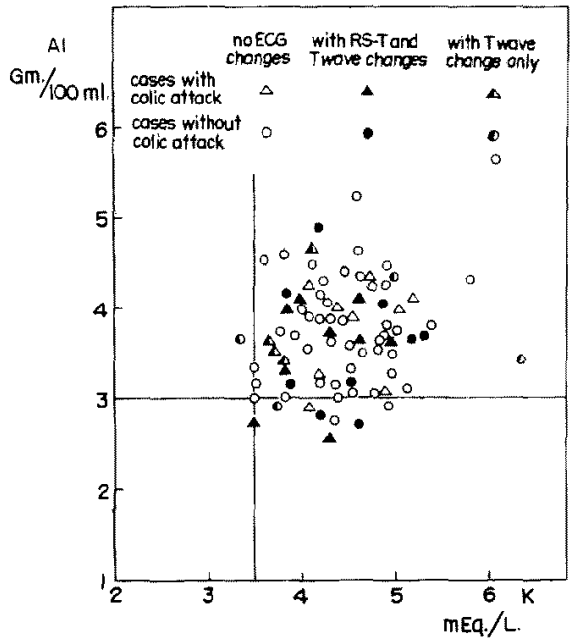

Fig. 2. Relationship of RS-T and $T$ changes to serum albumin and serum potassium in biliary tract diseases. 
obtained in 27 of 57 cases (47\%) with gastric, liver and esophageal cancer, in 12 of 19 cases $(63 \%)$ with liver cirrhosis and in 5 of 26 cases (19\%) with hepatitis, respectively.

As shown in Fig. 1, most cases with the RS-T and $\mathrm{T}$ changes were revealed of having hypalbuminemia lower than $3.0 \mathrm{Gm} .100 \mathrm{ml}$. and/or hypopotassemia lower than $3.5 \mathrm{mEq}$./L. The cases with hypalbuminemia showed principally the lowering of the $T$ wave alone, while most cases with hypopotassemia the depression of the RS-T segment accompanied with or

Table I. List of Cases with Biliary Tract Disease Showing the RS-T and/or T Changes during Colic Attack

\begin{tabular}{|c|c|c|c|c|c|c|}
\hline \multirow{2}{*}{$\begin{array}{l}\text { Case } \\
\text { No. }\end{array}$} & \multirow{2}{*}{$\begin{array}{l}\text { Age } \\
\text { Sex }\end{array}$} & \multirow{2}{*}{$\begin{array}{c}\text { Blood } \\
\text { pressure }\end{array}$} & \multicolumn{4}{|c|}{ Electrocardiographic findings } \\
\hline & & & during colic attack & $\begin{array}{l}\text { at the period } \\
\text { without attack }\end{array}$ & $\begin{array}{l}\text { in double } \\
\text { two-step test }\end{array}$ & in anoxia test \\
\hline 1 & $\begin{array}{l}19 \\
\mathrm{~F}\end{array}$ & $134 / 88$ & $\mathrm{~T}_{\mathrm{II}, \mathrm{a}, v_{\mathrm{F}}}$ flat & normal & & normal \\
\hline 2 & $\begin{array}{l}28 \\
F\end{array}$ & $118 / 64$ & $\begin{array}{l}\mathrm{ST}-\mathrm{T}_{\mathrm{I}, \mathrm{I}_{\mathrm{a}} \mathrm{V}_{\mathrm{F}}, \mathrm{V}_{4,5}} \\
\quad \text { depressed }\end{array}$ & normal & normal & \\
\hline 3 & $\begin{array}{l}40 \\
F\end{array}$ & $120 / 80$ & $\begin{array}{r}S T-T_{I, I I, a} v_{F} \\
\text { depressed }\end{array}$ & normal & & $\mathrm{T}_{11, \mathrm{~V}_{5}}$ depressed \\
\hline & & & $\begin{array}{l}T_{I I I, V_{3-5}} \text { inverted, } \\
T_{V_{\theta}} \text { flat }\end{array}$ & & & \\
\hline 4 & $\begin{array}{l}55 \\
\mathbf{M}\end{array}$ & $154 / 104$ & $\mathrm{ST}_{1 \mathrm{I}_{\mathrm{a}} \mathrm{v}_{\mathrm{F}}}$ depressed & normal & normal & \\
\hline 5 & $\begin{array}{l}55 \\
\mathrm{M}\end{array}$ & $150 / 100$ & $\begin{array}{l}\mathrm{ST}_{\mathrm{II}, \mathrm{a}} \mathrm{V}_{\mathrm{F}}, \mathrm{V}_{4-\mathrm{A}} \\
\text { depressed }\end{array}$ & $\begin{array}{l}\mathrm{ST}_{\mathrm{II}, i_{6}} \\
\text { slightly } \\
\text { depressed }\end{array}$ & & $\begin{array}{l}\text { marked depres- } \\
\text { sion of } \\
\mathrm{ST}_{\mathrm{II}, \mathrm{H}, \mathrm{V}_{\mathrm{s}}}\end{array}$ \\
\hline 6 & $\begin{array}{l}58 \\
F\end{array}$ & $125 / 60$ & $\begin{array}{l}\mathrm{ST}_{\mathrm{II}} \text { depressed } \\
\mathrm{T}_{\mathrm{II} \mathrm{C}_{\mathrm{B}} \mathrm{V}_{\mathrm{F}}} \text { flat }\end{array}$ & normal & normal & \\
\hline 7 & $\begin{array}{l}60 \\
\mathbf{F}\end{array}$ & $110 / 60$ & $\begin{array}{l}\mathrm{ST}_{\mathrm{II}} \text { depressed } \\
\mathrm{T}_{1 \mathrm{I}_{\mathrm{Q}} \mathrm{V}_{\mathrm{F}}} \text { flat }\end{array}$ & $\begin{array}{l}\mathrm{ST}_{\mathrm{II}} \\
\text { slightly } \\
\text { depressed }\end{array}$ & $\begin{array}{l}\mathrm{ST}-\mathrm{T}_{\mathrm{II}} \\
\text { depressed }\end{array}$ & \\
\hline 8 & $\begin{array}{l}21 \\
\mathrm{~F}\end{array}$ & $110 / 60$ & $\mathrm{ST}_{\mathrm{V}_{2-5}}$ depressed & normal & & \\
\hline 9 & $\begin{array}{l}24 \\
F\end{array}$ & $120 / 90$ & $\begin{array}{l}\mathrm{ST}-\mathrm{T}_{\mathrm{II}, \mathrm{a}} \mathrm{V}_{\mathrm{F}}, \mathrm{V}_{\mathrm{B}-\mathrm{a}} \\
\text { depressed }\end{array}$ & normal & & \\
\hline 10 & $\begin{array}{l}25 \\
F\end{array}$ & $130 / 62$ & $\begin{array}{l}\mathrm{ST}-\mathrm{T}_{\mathrm{II}, \mathrm{V}_{\mathrm{F}}} \\
\text { depressed }\end{array}$ & normal & & \\
\hline 11 & $\begin{array}{l}43 \\
\mathbf{F}\end{array}$ & $108 / 64$ & $\begin{array}{l}S T-T_{1 I, a} V_{F}, V_{4-a} \\
\text { depressd }\end{array}$ & normal & & \\
\hline 12 & $\begin{array}{l}60 \\
\mathbf{M}\end{array}$ & $110 / 60$ & $\begin{array}{l}\mathrm{ST}_{\mathrm{II}, \mathrm{V}_{5}} \text { markedly } \\
\text { depressed }\end{array}$ & $\begin{array}{l}\mathrm{ST}_{\mathrm{II}, \mathrm{V}_{5}} \\
\text { slightly } \\
\text { depressed }\end{array}$ & & \\
\hline 13 & $\begin{array}{l}41 \\
F\end{array}$ & $112 / 72$ & $\begin{array}{l}S T_{I I} \text { depressed } \\
T_{V_{4-0}} \text { flat }\end{array}$ & & & \\
\hline 14 & $\begin{array}{l}43 \\
\mathrm{M}\end{array}$ & $98 / 45$ & $\mathrm{~T}_{\text {II }}$ flat & & & \\
\hline
\end{tabular}


without the $\mathrm{T}$ wave changes. A few of the cases with the serum albumin and potassium level above the critical level were revealed to have the changes in the RS-T segment or $\mathrm{T}$ wave. Since most of such cases, however, had abnormally high or low blood pressure, their electrocardiographic findings should be interpreted in connection with the abnormal blood pressure.

\section{Biliary tract discascs}

The RS-T and $\mathrm{T}$ changes were observed in 27 of 83 cases (33\%) with cholelithiasis and/or cholecystitis.

As shown in Fig. 2, in most cases having the electrocardiographic changes the serum albumin and potassium were ranged above the critical level described in the foregoing section with a few exception. The changes in the RS-T segment were observed much more frequently than those in the $\mathrm{T}$ wave alone. These results may suggest that factors other than hypalbuminemia or hypopotassemia are responsible for the electrocardiographic findings and that the coronary disturbances probably play some role.

The electrocardiogram was recorded during colic attack in 23 cases, of which the RS-T or $\mathrm{T}$ findings appeared or were aggravated in 14 cases (61\%), as indicated in Table I. Nine of these cases had normal electrocardiogram during asymptomatic period.

The exercise or anoxia tests were carried out in 7 cases, which showed abnormal electrocardiograms during the attack and normal without attack or improvement after an operation. Positive results were obtained in 3 cases,

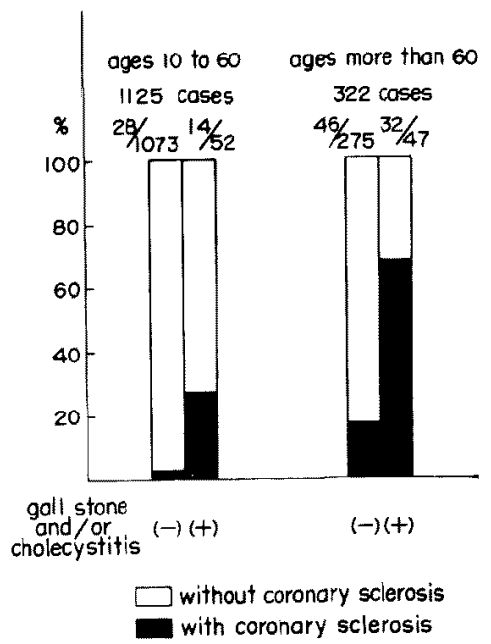

Fig. 3. Coexistence of gallbladder diseases and coronary sclerosis (autopsied cases in the Pathological Department of Tohoku University from 1950 to 1959).

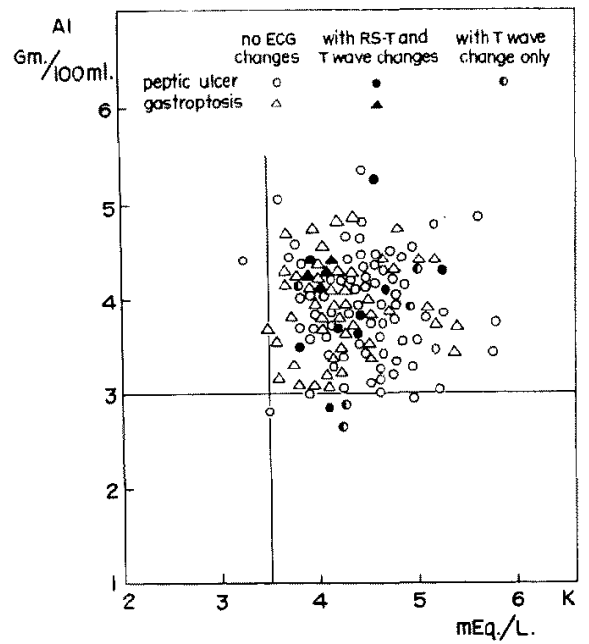

Fig. 4. Relationship of RS.T and T changes to serum albumin and serum potassium in peptic ulcer and gastroptosis. 
as listed in Table I.

The incidence of the association of the gallbladder diseases (gallstone and/or cholecystitis) with coronary artery disease was investigated from the autopsied materials and is shown in Fig. 3. Coronary sclerosis was more common in cases with gallbladder diseases than in the control series.

3. Peptic ulcer and gastroptosis

The changes in the RS-T segment and $T$ wave were observed in 14 of 93 cases $(15 \%)$ with peptic ulcer and in only 4 of 54 cases (7\%) with gastroptosis. Of the cases of peptic ulcer with electrocardiographic abnormalities, only 3 showed the hypalbuminemia lower than $3.0 \mathrm{Gm}$./ $100 \mathrm{ml}$, as seen in Fig. 4. The changes were improved after the amelioration of peptic ulcer, as the serum albumin level increased.

Fig. 5 indicates the incidence of lowering of the $T$ wave recorded in
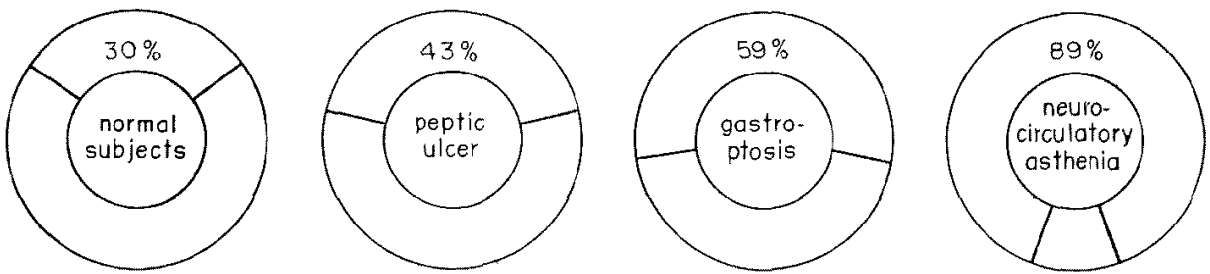

Fig. 5. Incidence of lowering of the $\mathrm{T}$ wave in the upright position in various conditions.

the upright position. This finding was observed in $43 \%$ of peptic ulcer and in $59 \%$ of gastroptosis, as compared with in $30 \%$ of normal subjects and in $89 \%$ of neurocirculatory asthenia.

\section{Discussion}

I. Hypopotassemia and hypalbuminemia in gastrointestinal cancer, liver cirrhosis and hepatitis

It is needless to say that the hypopotassemia will produce the RS-T and $\mathrm{T}$ changes. According to Goldberger, ${ }^{3)}$ the potassium level of about $3.5 \mathrm{mEq} . / \mathrm{L}$. will produce the changes. In our series, cases with gastrointestinal cancer, liver cirrhosis and hepatitis showed the RS-T and T changes when the potassium level was lower than the level pointed out by Goldberger.

On the other hand, the critical level of serum albumin causing the $T$ wave changes has been neither established nor yet discussed in detail. Wuhrmann ${ }^{4}$ pointed out that the dysproteinemia observed in liver cirrhosis, ulcerative colitis, sprue, myeloma, etc., produces the anatomical changes in the myocardium, which he named "Myokardose," and suggested that the 
lesion is responsible for the electrocardiographic changes characterized by "Verfliessen von ST und T," but he did not mention the actual level of serum protein which produces the electrocardiographic changes. In our series, the $\mathrm{T}$ wave changes were observed when the serum albumin level decreased lower than $3.0 \mathrm{Gm} / 100 \mathrm{ml}$. Therefore, hypalbuminemia is considered to be responsible for the $\mathrm{T}$ wave changes rather than dysproteinemia. Although we are unable to explain the actual cause of $T$ wave changes observed in cases with the hypalbuminemia, it may be assumed that the nutritional or biochemical disorders may change the intracellular metabolic process in the myocardium and, in consequence, affect the duration of the myocardial excitation and result in the $\mathrm{T}$ wave changes.

At any rate, the hypopotassemia on the one hand and the hypalbuminemia on the other hand are considered to be contributing factors producing the changes in the RS-T segment and T wave in cases with gatrointestinal cancer, liver cirrhosis and hepatitis.

\section{Biliary tract diseases and coronary disturbances}

Various concepts have been postulated concerning the relationship between biliary tract disorders and coronary disturbances.

The gallbladder and cardiovascular systems are related physiologically. Both are innervated by the autonomic nervous system and are subject to reflexes of the sympathetic and parasympathetic systems. Gilbert et al.5),6) have shown that irritation of the gallbladder in lightly anesthetized dog may reduce the coronary blood flow and that this effect may be abolished by vagal section or atropine. He also reported ${ }^{7)}$ that the decrease in coronary blood flow was observed by distending the gallbladder or its duct in the decerebrated dog. Anrep, ${ }^{8)}$ Greene, ${ }^{9)}$ and others have pointed out that the vagus nerve exerts a tonic vasoconstrictive effect on the coronary vessels. From these findings, the concept that reflex originating from the biliary tract may produce the vagal vasoconstriction of the coronary arteries ${ }^{10)}$ has been widely accepted. If this is correct, the transient changes in the RS- $\mathrm{T}$ segment and the $\mathrm{T}$ wave are expected to appear during a colic attack and to disappear after its subsiding. In our series, 14 cases of biliary tract diseases showed the appearance or aggravation of the RS-T and/or $T$ changes during the attack and the regression of these findings was observed in 9 cases after the subsidence of the acute gallbladder attack or following cholecystectomy. Similar observations in the past ${ }^{11)-15)}$ may support the concept described above.

Another hypothesis is that pre-existing latent coronary insufficiency probably due to the coronary sclerosis may become manifest during colic attack. In this regard, the association of the gallbladder diseases with coronary artery disease has been investigated. Breyfogle, ${ }^{16)}$ in a statistical 
study of 1,493 necropsy records, concluded that there was "a striking and positive association, regardless of age or sex, between gallbladder disease and coronary artery disease." Walsh et al. ${ }^{17}$ ) found that the association of gallbladder disease with coronary artery disease was twice as common as their separate occurrence. Tennant and Zimmerman ${ }^{18)}$ also reported a significant coincidence of the two conditions in the study of 1,600 necropsied cases. In our series based on 1,447 necropsy records, coronary sclerosis was much more prevalent in cases having gallstone and/or cholecystitis than in those without them.

Walters and Master ${ }^{19)}$ reported that an acute gallbladder attack may precipitate acute coronary insufficiency through a vagovagal reflex in patients having pie-existing coronary artery disease, and have an opinion that coronary artery disease should not be excluded in patients with acute gallbladder disease, unless two-step test is found to be normal. Our observations, in which positive results were obtained in 3 of 7 cases examined by double two-step or anoxia tests, may support this view.

Thus, the RS-T and $\mathrm{T}$ changes in the biliary tract diseases can be attributed to the coronary disorders, functional, organic or both.

The focal infection may be another matter for consideration, although it was not referred here.

3. Peptic ulcer, gastroptosis and hypotension

Since the study by Nordenfelt ${ }^{20}$ it has been known that $\mathrm{T}$ wave is lowered or inverted in the upright position in some patients with neurocirculatory asthenia or hypotension. It is also well-known that the hypotension is observed not infrequently in the cases with peptic ulcer or gastroptosis. In our series, $48 \%$ of peptic ulcer and $81 \%$ of gastroptosis had hypotension, and lowering of the $\mathrm{T}$ wave in the upright position was observed much more frequently in the hypotensive group than in the normotensive in both diseases.

As pointed out by Kimura in his previous report, ${ }^{21)}$ some of the cases with hypotension show the RS-T and T changes even in the recumbent position and such findings can be interpreted to be a high degree of the $\mathrm{T}$ changes in the upright position. Consequently, the RS-T and T changes observed in the recumbent position in peptic ulcer and gastroptosis without hypalbuminemia or hypopotassemia may be understood to be identical with the changes observed in certain cases with hypotension and attributed to the dysregulation of the autonomic nervous system or the circulatory dysfunction without organic changes in the heart.

\section{SUMMARY}

(1) The RS-T and T changes were observed in 27 of 57 cases $(47 \%)$ 
with gastrointestinal cancer, in 12 of 19 cases (63\%) with liver cirrhosis, and in 5 of 26 cases $(19 \%)$ with hepatitis, respectively. Most cases with RS-T changes were revealed to have hypopotassemia lower than $3.5 \mathrm{mEq} / \mathrm{L}$., while cases with lowering of the $\mathrm{T}$ wave alone had hypalbuminemia lower than $3.0 \mathrm{Gm} . / 100 \mathrm{ml}$. It was assumed that the hypalbuminemia rather than dysproteinemia on the one hand and hypopotassemia on the other hand might be contributing factors to the RS-T and $T$ changes in these diseases.

(2) In biliary tract diseases, the RS-T and T changes were observed in 27 of 83 cases (33\%). The serum albumin and potassium levels were ranged mostly above the critical level regardless of the electrocardiographic findings. Of 23 cases, in which the electrocardiogram was recorded during colic attack, the RS-T or $\mathrm{T}$ changes appeared or became aggravated in 14 cases. The anoxia or double two-step tests revealed the positive results in 3 of 7 cases examined. In autopsied series, coronary sclerosis was more common in cases with gallbladder diseases than in the control. From these findings, the RS-T and $\mathrm{T}$ changes in the biliary tract diseases can be attributed to the coronary disorders, which may be functional, organic or both.

(3) In peptic ulcer, the RS-T and T changes were observed in 14 of 93 cases $(15 \%)$ and in gastroptosis in 4 of 54 cases $(7 \%)$. It is known that these diseases frequently have hypotension and that $\mathrm{T}$ wave often becomes flat or inverted in upright position in the hypotensive patients. In our series, $49 \%$ of peptic ulcer and $81 \%$ of gastroptosis were hypotensive and lowering of the $\mathrm{T}$ wave in upright position was seen in $43 \%$ of the former and in $53 \%$ of the latter. From these viewpoints, the RS-T or $\mathrm{T}$ changes observed in these diseases in recumbent position may be interpreted to be a higher degree of the findings observed in upright position and attributed to the autonomic nervous dysregulation or circulatory dysfunction, as interpreted in hypotension.

\section{Acknowledgement}

The authors wish to express their thanks to Prof. K. Akazaki and Prof. N. Suwa of the Pathological Department of Tohoku University Medical School for the privilege of reviewing the necropsy records.

This study was supported, in part, by a grant in aid for Fundamental Scientific Research from the Education Ministry.

\section{REFERENCES}

1. Lepeschkin, E.: Modern Electrocardiography, Vol. 1., Baltimore, 1951

2. Kimura, E., Nakamura, M., and Yamazaki, T.: in preparation. 
3. Goldberger, E.: Unipolar Lead Electrocardiography and Vectorcardiography, 3rd ed., Philadelphia, 1953.

4. Wuhrmann, F.: Die Myokardose, Basel, 1956.

5. Gilbert, N.C., Fenn, G. K., and LeRoy, G. V.: J. A. M. A. 115: 1962, 1940.

6. Gilbert, N. C., LeRoy, G. V., and Fenn, G. K.: Am. Heart J. 20: 519, 1940.

7. Gilbert, N. C.: Bull. N. Y. Acad. Med. 18: 83, 1942.

8. Anrep, G. B.: Physiol. Rev. 6: 596, 1926.

9. Greene, C. W.: Am. Heart J. 11: 592, 1936.

10. Grittenden, P. J. and Ivy, A. C. : Am. Heart J. 8: 507, 1933.

11. Breitwieser, E. R.: Am. J. Med. Sci. 213: 598, 1947.

12. Clarke, N.E.: Am. Heart J. 29: 628, 1947.

13. Fitz-Hugh, T., Jr. and Wolferth, C. C.: Ann. Surg. 101: 478, 1935.

14. Moschkowitz, E. : J. Mt. Sinai Hosp. N. Y. 10: 632, 1944.

15. Weiss, M. M. and Hamilton, J. E.: Surgery 6: 893, 1939.

16. Breyfogle, H.S.: J. A. M. A. 114: 1434, 1940.

17. Walsh, B.J., Bland, E. F., Taquini, A. C. and White, P. D.: Am. Heart J. 21: 689, 1941.

18. Tennant, R., Jr. and Zimmerman, H. M.: Yale J. Biol. 3: 495, 1931.

19. Walters, M. B. and Master, A. M. : Surg. Gynec. \& Obst. 94: 1.52, 1952.

20. Nordenfelt, O.: Acta med. Scand., Suppl. 119, 1941.

21. Kimura, E.: Jap. Circulat. J. 25: 161, 1961. 